\title{
Zoomed out? Depersonalization is Related to Increased Digital Media Use During the COVID-19 Pandemic Lockdown
}

\author{
Anna Ciaunica ${ }^{1,2,3^{*}}$, Luke McEllin ${ }^{4,5^{+}}$, Julian Kiverstein ${ }^{6,7}$, Vittorio Gallese ${ }^{8}$, Jakob \\ Hohwy ${ }^{9,10}$, Mateusz Woźniak ${ }^{5,9 *}$ \\ 1Centre for Philosophy of Science, University of Lisbon, Campo Grande, 1749-016 Lisbon, Portugal \\ 2 Institute of Philosophy, University of Porto, via Panoramica s/n 4150-564, Porto Portugal \\ 3 Institute of Cognitive Neuroscience, University College London, WC1N 3AR, London, UK \\ 4 University of Warwick \\ 5 Social Mind Center, Department of Cognitive Science, Central European University, Vienna, Austria \\ 6 Department of Psychiatry, Amsterdam University Medical Centre, Meibergdreef 5, 1105AZ, Amsterdam, \\ The Netherlands \\ 7. Amsterdam Brain and Cognition, University of Amsterdam \\ 8 Department of Medicine and Surgery, Unit of Neuroscience, University of Parma, Italy \\ 9 Cognition and Philosophy Lab, Department of Philosophy, Monash University, Melbourne, Australia \\ 10 Monash Centre for Consciousness \& Contemplative Studies, Monash University, Melbourne, Australia
}

\section{Corresponding authors:}

E-mail: Dr Anna Ciaunica a.ciaunica@ucl.ac.uk

E-mail: Dr Mateusz Woźniak mgwozniak@gmail.com

${ }^{+}$These authors contributed equally to this work

\begin{abstract}
Depersonalisation is a common dissociative experience characterised by distressing feelings of being detached or 'estranged' from one's self and body and/or the world. The COVID-19 pandemic forced millions of people to socially distance from others and to change life habits. We have conducted an online study on 622 participants worldwide to investigate the relationship between digital media-based activities and distal social interactions in influencing peoples' sense of self during the lockdown as opposed to before the pandemic. We found that increased use of digital media-based activities and online social e-meetings correlated with higher feelings of depersonalisation. We also found that people reporting higher experiences of depersonalisation also reported enhanced vividness of negative emotions (as opposed to positive emotions). Our study also reveals a weak negative correlation between the frequency of physical exercise during the lockdown and the occurrence of depersonalisation experiences. Finally, participants who reported that lockdown influenced their life to greater extent had higher occurrences of depersonalisation experiences. Our findings may help address key questions regarding well-being during a lockdown, in the general population. Our study points to potential risks related to an overly sedentary and hyper-digitalized life habits that may induce feelings of living in one's 'head' (mind), disconnected from one's body, self and the world.
\end{abstract}

Keywords: depersonalization, digital media, COVID-19 lockdown, pandemic, bodily self, social interactions 


\section{Introduction}

The sense of self, the subjective experience of being an 'I' or a 'self' bound to my body as distinct from the world and others, is a key feature of our mental life (Gallagher 2000; Damasio 2000; Hohwy 2007; Blanke \& Metzinger 2009; see Quin et al. 2020 for a review). Depersonalisation (DP henceforth) is a common dissociative experience characterised by profound alterations of one's sense of self (Sierra \& Berrios 1997). DP induces distressing feelings of being detached or 'estranged' from one's self and body and/or one's surroundings (derealisation) (Sierra \& David 2011): "I look in the mirror and it doesn't feel like myself I'm looking at. It's like I'm floating, not actually experiencing the world, and slowly fading away into nothing. It's like I'm on autopilot in somebody's else body" (Perkins 2021 :198).

This dramatic 'split' between the self, the body and the world is often and strikingly reported by DP people as 'having a pane of glass' interposed between one's self, body and the world (Simeon \& Abugel, 2006; Sierra 2009), affecting the sense of 'realness' or presence of being immersed in a real world here and now (Seth et al. 2011). Importantly, people experiencing DP report a significant impact of this self-detachment on the quality of their social and emotional life: "Feeling unreal and disconnected from my body and the world around me caused me to lose interest in the people and hobbies I used to love" (Perkins 2021: 190). These distressing feelings of being estranged from one's self and ensuing social isolation and distancing from others (Simeon \& Abugel 2006; Sierra 2009) is a common complaint among people experiencing depersonalisation.

In December 2019, the first cases of COVID-19 were reported in Wuhan, China and a state of pandemic has been officially declared by the Emergency Safety Committee of the International Health Regulations. Intriguingly, the COVID-19 pandemic presents us with a situation in which people are strongly encouraged to isolate from others, to maintain social distancing. While experimentally induced social isolation and its impact on one's self is ethically impossible to study in the lab, the current exceptional context allows examination 'in the wild' of whether lockdownrelated changes affect people's sense of self and presence in the world, and particularly feelings of depersonalisation.

The pandemic has forced millions of people to drastically change their life habits due to worldwide restrictions of movement and social interactions in person (see Froese et al. 2021 for a recent discussion of cross-cultural subjective reports). Numerous studies suggest that these changes significantly impact people's mental health worldwide (Brooks et al. 2020; Xiong et al. 2020; Alzueta et al., 2021; von Mohr et al. 2021). The ensuing uncertainty and social distancing requirements (Carel et al. 2020) have increased stress and anxiety levels in the general population (Salari et al. 2020), and seems to aggravate symptoms for those with pre-existing mental health conditions (Rubin \& Wessely 2020).

In the pre-pandemic context, DP had a prevalence of around 1-2\% of the population (Hunter et al. 2004; Michal et al. 2007; Lee et al. 2012), which is comparable to that of schizophrenia, for example (Hunter et al. 2017). Transient occurrences of depersonalization episodes have been reported by almost $50 \%$ of college students (Dixon, 1963). DP typically co-occurs with highly traumatic events, or as symptoms of anxiety, panic, and depression (see Salami et al. 2020 for a recent discussion). Emotional flatness or numbness, as well as atypical emotional processing are core features of depersonalisation (Medford 2012; Sierra et al., 2012).

Despite this high prevalence, little is known about the relationship between social isolation and feelings of depersonalisation. Moreover, no study to date has examined the relationship between 
being estranged from others (due to events like COVID-19 lockdown restrictions), life habits changes, and feelings of depersonalisation. This gap is surprizing because numerous pre-pandemic self-reports from people diagnosed with clinical Depersonalisation Disorder point to the importance of maintaining close contact and proximal interactions with the physical and social environment in order to enhance one's sense of self: "When the depersonalisation is very deep, (...) it feels like that constant source of interaction is the only thing that allows me to maintain a connection with the world. I'll also seek physical contact with whoever I'm with." (Ciaunica \& Charlton 2018); "I really like when people scratch me or twist my arms or just touch me. It puts me back in my body and makes me feel cared for" (Perkins 2021:87).

Previous work that has emphasized the importance of dynamic and proximal embodied interactions with the physical and social environment on people's sense of self and sense of presence in the world (de Jaegher \& di Paolo 2007; Schilbach et al. 2013; Ciaunica \& Fotopoulou 2017; Ciaunica et al. 2021). There is growing consensus that bodily self-awareness is not an awareness of the body in passive isolation from the physical and social world. Indeed, both classic phenomenologists such as Husserl (1952/1989; ) and Merleau-Ponty (1962/2012) and researchers working within cognitive science insist on the idea that bodily self-awareness ought to be understood primarily in relation to the environment, and to other people (Legrand 2006; De Jaegher and Di Paolo 2007; Gallese 2014; Ciaunica 2016; Kiverstein 2020; Ciaunica et al. 2021a).

The importance of rhythmic behaviour and mutual co-regulation via social interactions on one's self is nowadays widely acknowledged (Sebanz et al. 2006; Richardson et al. 2007;). There is also increasing acknowledgement of the observation that everyday events are commonly multimodal in nature, which raises the important question of how multimodal features are integrated to constitute the sense of self and presence in the world (see Zmigrod \& Hommel 2013 for review; Deroy et al. 2014). Indeed, multisensory integration of sensory signals arising from both inside and outside our bodies is fundamental to building a cohesive representation of our body, self and the world (Park \& Blanke 2009; Tsakiris 2017; Fotopoulou \& Tsakiris 2017).

Importantly, people experiencing depersonalisation report an inability to feel or judge where the body ends or begins; a lack of sensation or feedback from the body; inability to judge one's position in space and one's movements; or sensations of being divorced from one's body, all of which significantly alter the quality of mental and social life (Simeon \& Abugel 2006; Sierra and David 2011; Hunter et al. 2017). These alterations constrain people's ability to feel fully present in their lives; to relate to others; and to participate in daily activities. It is crucial thus to address this question because, as one person with DP strikingly puts it: "a disorder that makes you feel invisible is invisible in society" (Perkins 2021:193).

We have conducted an online study to investigate the relationship between digital media-based activities and distal social interactions in influencing peoples' sense of self during the lockdown as opposed to before the pandemic. Crucially, the COVID-19 pandemic forced millions of people to significantly decrease their physical activities and social interactions in person inside and outside one's home. While technology-based activities and online internet-based exchanges is currently ubiquitous, especially for youth, particularly as a tool for socialization, the exceptional situation created the context of a considerably increased use of digital activities and distal communication platforms (Dimmock et al. 2020).

Specifically, we examined whether people who spend more time using indoors digital, technologybased platforms for both activities and social interactions during the lockdown may also show increased depersonalisation traits. We also examined whether people who spend more time doing outdoors physical activities (e.g. walking, running, playing football, etc.), as well as manual work involving rich multisensory experiences (such as gardening, cooking, pottery, etc.), may show 
decreased DP traits. In addition, we aimed at exploring what aspects of our self-experiences and activities are most impacted during these long episodes of radical life changes and social distancing. We also looked at the impact of these lockdown related changes on the perceived vividness of our positive and negative emotions.

We built the study hypothesis upon the notion that our sense of self and presence in the world critically depends on multisensory rich and proximal embodied interactions with the physical and social environment (Ionta et al. 2011; Deroy et al. 2014; Tsakiris 2017; Ciaunica \& Fotopoulou 2017; Ciaunica et al. 2021). By contrast, sedentary and multisensory impoverished activities, as well as distal social exchanges may make people feel more self-detached, and self-estranged, living more in their 'heads' (minds) and less in their bodies, and consequently feeling less 'real'.

\section{Methods}

\subsection{Participants}

Power analysis conducted using $\mathrm{G}^{*}$ Power 3.1.9.2 revealed that in order to detect correlations equal to or stronger than $\mathrm{rho}=0.15$ with alpha $=0.05$ and $\mathrm{beta}=0.95$ the required sample size needs to be at least 571 participants. We estimated our target sample size to be approximately 640 people.

We recruited 691 people from the Prolific crowdsourcing platform. Data collection took place between 23 April and 8 May 2021. For the analysis of effects of COVID-19 lockdown we excluded participants that reported that they hadn't experienced lockdown during the last 6 months for more than one month and those that left this question unanswered. Our final sample consisted of 622 participants. The mean age of all participants was 31.5 years $(\mathrm{SD}=12.2$, Median=27, range 18-78). 257 of participants were female, 358 were male and 74 did not disclose their gender. Participants represented predominantly European nationalities: UK (220 participants), Poland (93), Portugal (65), USA (34), Italy (33), the Netherlands (22), Greece (18), South Africa (14), and Germany (10). The remaining participants represented diverse nationalities from around the world. 73 participants did not disclose their nationality on Prolific. The places of residence of participants were predominantly European countries (550 participants), with the exception of Australia (1), Canada (7), Chile (1), Israel (3), Mexico (5), South Africa (18) and USA (33). 71 participants did not indicate their country of residence on Prolific.

Informed consent was obtained from all participants before the start of the experiment according to procedures approved by the Monash University Human Research Ethics Committee (MUHREC).

\subsection{Measures}

Our online survey used two measures. (1) All participants first completed the Cambridge Depersonalization Scale (CDS-29: (Sierra \& Berrios, 2000)). CDS-29 is a 29 items standard questionnaire used to evaluate the severity of occurrence of depersonalization experiences by asking participants to estimate their frequency and duration in the past six months. The total score (between 0 and 290) points is calculated by summing over all items. CDS-29 has good statistical properties (Aponte-Soto, Vélez-Pastrana, Martínez-Taboas, \& González, 2014; Fagioli et al., 2015; Migliorini et al., 2012; Sierra \& Berrios, 2000; Sugiura et al., 2009) with internal reliability for different language versions reported between 0.89-0.94 (Cronbach alpha). Moreover, previous research has extracted four subscales from CDS-29 (Sierra, Baker, Medford, \& David, 2005): Anomalous Body Experience, Emotional Numbing, Anomalous Subjective Recall, and Alienation from Surroundings. Given that in our sample all of these subscales correlated with each other more strongly (correlations between factors from $r=0.61$ to 0.66 ) than in (Sierra et al., 2005) who reported correlations between $\mathrm{r}=0.23$ and 0.34 , we decided to use only the full total score. 
(2) The second measure used in our study was a custom-designed lifestyle survey asking about life activities before and during the COVID-19 pandemic. Table 1 presents the full list of questions.

First, participants were asked whether they experienced COVID-19 related lockdown during the last 6 months (the same duration covered by the CDS-29). We included this question in order to screen out participants that were not affected by lockdown. The second question asked them to evaluate to what extent they feel that the lockdown influenced their life on a 5-point Likert scale. In the main part of the survey, participants were asked to separately evaluate how many hours per week they used to spend (a) before the pandemic and (b) during the last 6 months (during the pandemic) doing each of eight activities presented in Table 1. The questions were selected based on our research hypotheses regarding what activities might influence depersonalization, such as in-person versus digital social activities, as well as physical activities versus media use. Finally, at the end of the survey participants were asked about how the COVID-19 lockdown influenced the vividness of their emotional experiences, separately for positive and negative emotions.

\section{Table 1. Lockdown Questionnaire}

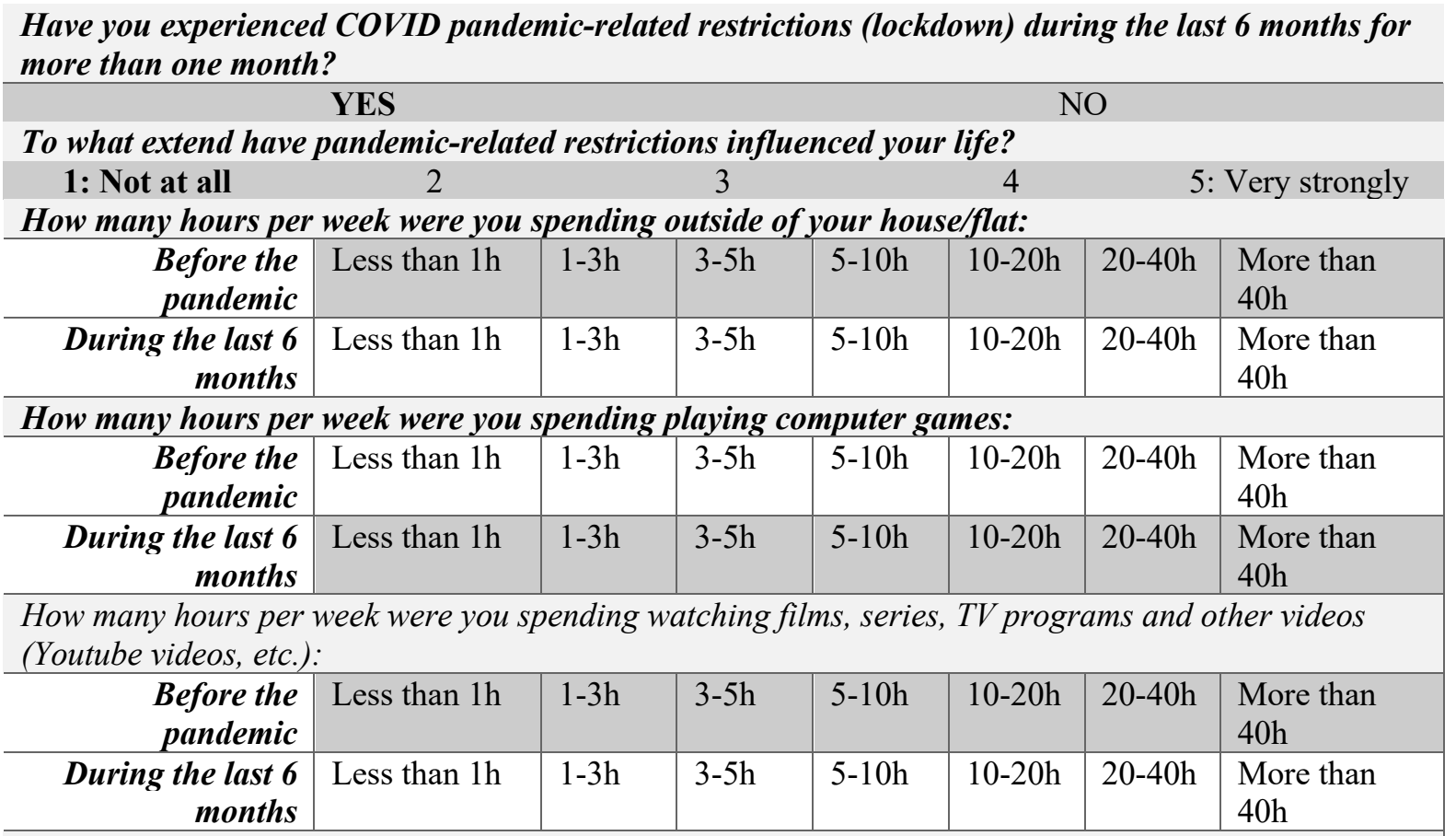

How many hours per week were you spending meeting with other people online (video-chatting via virtual platforms such as Zoom, Microsoft Teams, Skype, etc.)

\begin{tabular}{|r|l|l|l|l|l|l|l|}
\hline $\begin{array}{r}\text { Before the } \\
\text { pandemic }\end{array}$ & Less than $1 \mathrm{~h}$ & $1-3 \mathrm{~h}$ & $3-5 \mathrm{~h}$ & $5-10 \mathrm{~h}$ & $10-20 \mathrm{~h}$ & $20-40 \mathrm{~h}$ & $\begin{array}{l}\text { More than } \\
40 \mathrm{~h}\end{array}$ \\
\hline $\begin{array}{r}\text { During the last 6 } \\
\text { months }\end{array}$ & Less than 1h & $1-3 \mathrm{~h}$ & $3-5 \mathrm{~h}$ & $5-10 \mathrm{~h}$ & $10-20 \mathrm{~h}$ & $20-40 \mathrm{~h}$ & $\begin{array}{l}\text { More than } \\
40 \mathrm{~h}\end{array}$ \\
\hline
\end{tabular}

How many hours per week were you spending meeting with other people in person OUTSIDE your flat/house:

\begin{tabular}{r|l|l|l|l|l|l|l|}
\hline $\begin{array}{r}\text { Before the } \\
\text { pandemic }\end{array}$ & Less than $1 \mathrm{~h}$ & $1-3 \mathrm{~h}$ & $3-5 \mathrm{~h}$ & $5-10 \mathrm{~h}$ & $10-20 \mathrm{~h}$ & $20-40 \mathrm{~h}$ & $\begin{array}{l}\text { More than } \\
40 \mathrm{~h}\end{array}$ \\
\hline $\begin{array}{r}\text { During the last 6 } \\
\text { months }\end{array}$ & Less than 1h & $1-3 \mathrm{~h}$ & $3-5 \mathrm{~h}$ & $5-10 \mathrm{~h}$ & $10-20 \mathrm{~h}$ & $20-40 \mathrm{~h}$ & $\begin{array}{l}\text { More than } \\
40 \mathrm{~h}\end{array}$ \\
\hline
\end{tabular}

How many hours per week were you spending meeting with other people in person IN your flat/house (including the people that you live with):

\begin{tabular}{r|r|l|l|l|l|l|l|} 
(including the people that you live with): \\
$\begin{array}{r}\text { Before the } \\
\text { pandemic }\end{array}$ & Less than $1 \mathrm{~h}$ & $1-3 \mathrm{~h}$ & $3-5 \mathrm{~h}$ & $5-10 \mathrm{~h}$ & $10-20 \mathrm{~h}$ & $20-40 \mathrm{~h}$ & $\begin{array}{l}\text { More than } \\
40 \mathrm{~h}\end{array}$ \\
\hline $\begin{array}{r}\text { During the last } 6 \\
\text { months }\end{array}$ & Less than $1 \mathrm{~h}$ & $1-3 \mathrm{~h}$ & $3-5 \mathrm{~h}$ & $5-10 \mathrm{~h}$ & $10-20 \mathrm{~h}$ & $20-40 \mathrm{~h}$ & $\begin{array}{l}\text { More than } \\
40 \mathrm{~h}\end{array}$ \\
\cline { 2 - 7 }
\end{tabular}




\begin{tabular}{|c|c|c|c|c|c|c|c|}
\hline \multicolumn{8}{|c|}{ How many hours per week were you spending doing physical activity: } \\
\hline $\begin{array}{l}\text { Before the } \\
\text { pandemic }\end{array}$ & Less than $1 \mathrm{~h}$ & $1-3 h$ & $3-5 \mathrm{~h}$ & $5-10 \mathrm{~h}$ & $10-20 \mathrm{~h}$ & $20-40 \mathrm{~h}$ & $\begin{array}{l}\text { More than } \\
40 \mathrm{~h}\end{array}$ \\
\hline $\begin{array}{r}\text { During the last } 6 \\
\text { months }\end{array}$ & Less than $1 \mathrm{~h}$ & $1-3 \mathrm{~h}$ & $3-5 \mathrm{~h}$ & $5-10 \mathrm{~h}$ & $10-20 \mathrm{~h}$ & $20-40 \mathrm{~h}$ & $\begin{array}{l}\text { More than } \\
40 \mathrm{~h}\end{array}$ \\
\hline \multicolumn{8}{|c|}{$\begin{array}{l}\text { How many hours per week were you spending doing manual works (for example: gardening, painting, } \\
\text { pottery, playing an instrument): }\end{array}$} \\
\hline $\begin{array}{l}\text { Before the } \\
\text { pandemic }\end{array}$ & Less than $1 \mathrm{~h}$ & $1-3 h$ & $3-5 h \quad 5$ & $5-10 \mathrm{~h}$ & $10-20 \mathrm{~h}$ & $20-40 \mathrm{~h}$ & $\begin{array}{l}\text { More than } \\
40 \mathrm{~h}\end{array}$ \\
\hline $\begin{array}{r}\text { During the last } 6 \\
\text { months }\end{array}$ & Less than $1 \mathrm{~h}$ & $1-3 h$ & $3-5 \mathrm{~h}$ & $5-10 \mathrm{~h}$ & $10-20 \mathrm{~h}$ & $20-40 h$ & $\begin{array}{l}\text { More than } \\
40 \mathrm{~h}\end{array}$ \\
\hline \multicolumn{8}{|c|}{ How do you experience your POSITIVE EMOTIONS (for example: happiness, hope, joy, love)? } \\
\hline \multicolumn{2}{|c|}{$\begin{array}{l}\text { 1: I experience them less } \\
\text { vividly than before the } \\
\text { pandemic }\end{array}$} & \multicolumn{2}{|c|}{$\begin{array}{l}\text { 3: I experience } \\
\text { them similarly as } \\
\text { before the } \\
\text { pandemic }\end{array}$} & & \multicolumn{2}{|c|}{$\begin{array}{l}\text { 5: I experience them more } \\
\text { vividly than before the } \\
\text { pandemic }\end{array}$} \\
\hline \multicolumn{6}{|c|}{ How do you experience your NEGATIVE EMOTIONS (for example: sadness, anger, fear, disgust)? } & & \\
\hline \multicolumn{2}{|c|}{$\begin{array}{l}\text { 1: I experience them less } 2 \\
\text { vividly than before the } \\
\text { pandemic }\end{array}$} & \multicolumn{2}{|c|}{$\begin{array}{l}\text { 3: I experience } \\
\text { them similarly as } \\
\text { before the } \\
\text { pandemic }\end{array}$} & 4 & \multicolumn{3}{|c|}{$\begin{array}{l}\text { 5: I experience them more } \\
\text { vividly than before the } \\
\text { pandemic }\end{array}$} \\
\hline
\end{tabular}

\subsection{Procedure}

The study was programmed in Javascript using PsychoJS and hosted on the Pavlovia hosting service. Participants always started with completing the CDS-29 questionnaire, which was then followed with the survey asking about lifestyle before and during the Covid pandemic. Questions were displayed individually and there was no possibility to return to previous questions. After completing the study, participants were debriefed via instruction displayed on the screen. They also received information about whether their score in CDS-29 was relatively high (if above 50) or low (below 20), and referred to a specific page for further information about depersonalization disorder.

\section{4. Data analysis}

Data processing and analysis was conducted using custom scripts written in Python. Bayesian analyses were conducted using JASP 0.9.0.1. For estimation of life habits before and during the lockdown we used (a) participants' responses about the frequency of each behavior during the last 6 months as indices of their life habits during the lockdown, and (b) the difference between the frequency of each activity before and during the pandemic measured as: frequency during the last 6 months minus frequency before the pandemic. Due to the fact that frequencies were measured on an ordinal scale, all analyses involving them were conducted using non-parametric statistical methods: Kendall's tau B for correlations, and Wilcoxon's test for group comparisons.

\section{Results}

The survey asking participants about their life habits during the COVID-19 lockdown showed that out of the eight selected activities participants reported spending most time (a) watching noninteractive audiovisual media (movies, series, TV, internet videos) with median indicating that typical participant was spending 10-20h weekly on this activity (Figure 1). (b) The second most time-engaging activity during lockdown in our group was participating in online meetings (median $5-10 \mathrm{~h} /$ week), followed by (c) playing computer games (median 3-5h/week, but with very balanced distribution of responses across participants) and (d) spending time outside one's place of residence (median 3-5h/week). Participants reported a median of 1-3h/week doing physical exercises and 
doing manual work, and less than median $1 \mathrm{~h} /$ week meeting people outside or inside their place of residence.

(A) Time spent performing investigated activities during the COVID-19 lockdown
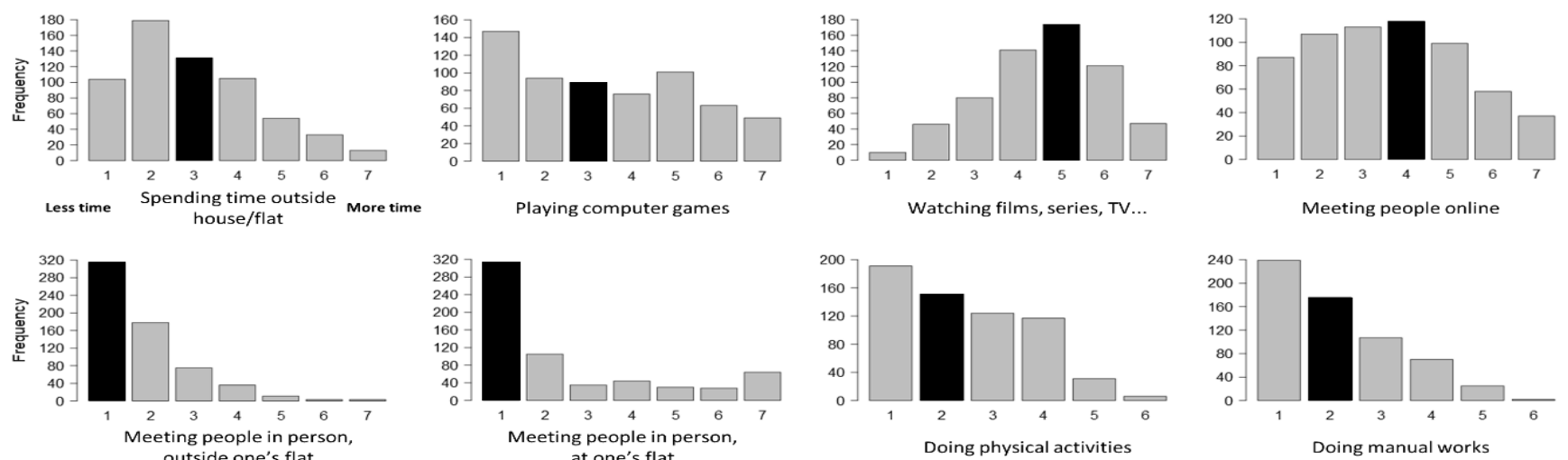

Explanation of time

at one's flat

Doing physical activities

Doing manual works Explanatio

\begin{tabular}{ccccccc}
\hline $\mathbf{1}$ & $\mathbf{2}$ & $\mathbf{3}$ & $\mathbf{4}$ & $\mathbf{5}$ & $\mathbf{6}$ & $\mathbf{7}$ \\
\hline Less than $1 \mathrm{~h}$ & $\mathbf{1 - 3 h}$ & $3-5 \mathrm{~h}$ & $5-10 \mathrm{~h}$ & $10-20 \mathrm{~h}$ & $20-40 \mathrm{~h}$ & More than 40h \\
\hline
\end{tabular}

(B) Change in time spent performing investigated activities from before the lockdown
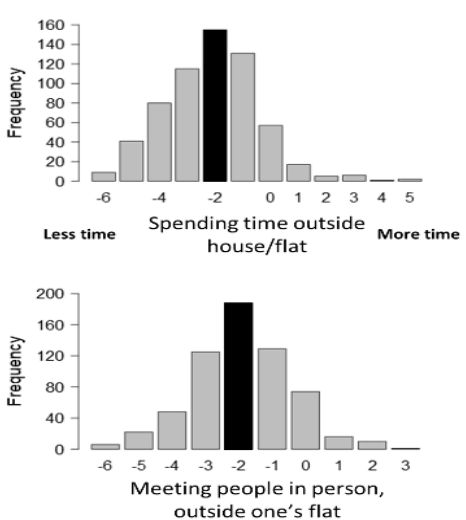

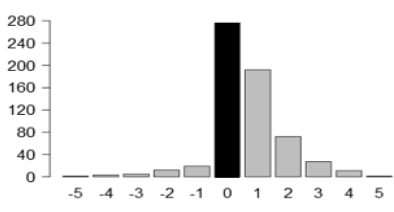

Playing computer games

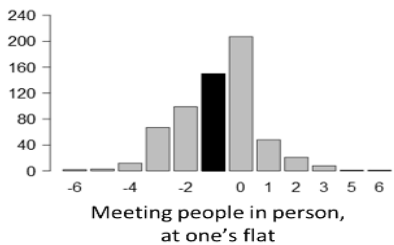

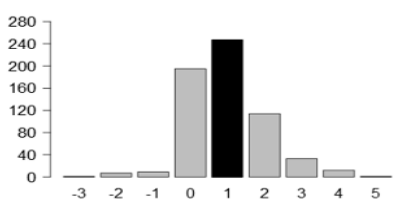

Watching films, series, TV...

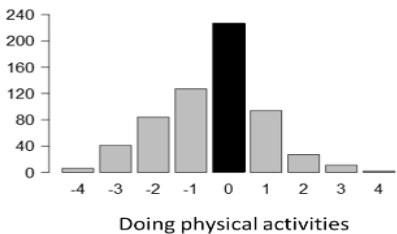

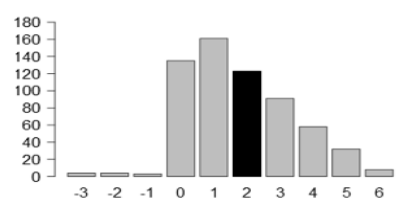

Meeting people online

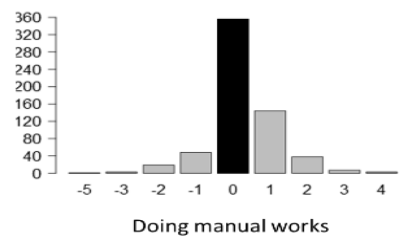

Figure 1. Distribution of weekly time spent performing investigated activities during lockdown (top part) and the change in time spent doing these activities between lockdown and before the COVID-19 pandemic started (bottom part). The change in time spent is indicated in the number of categories that changed - negative values indicate spending less time on a given activity during the lockdown than before, and positive values the opposite. Black bars indicate median values.

When comparing their lifestyle between the lockdown and before the pandemic, the largest decrease of activity was in the amount of time spent outside of one's place of residence ( $\mathrm{W}(620)=1.5+\mathrm{e} 6$, $\mathrm{p}<0.001$; median -2 categories: from 10-20h to 3-5h/week), meeting people outside one's house or flat $(\mathrm{W}(621)=1.4+\mathrm{e} 6, \mathrm{p}<0.001$; median -2 categories: from $3-5 \mathrm{~h}$ to less than $1 \mathrm{~h} /$ week $)$, and meeting people at one's flat or house $(\mathrm{W}(621)=7.2+\mathrm{e} 5, \mathrm{p}<0.001$; median -1 category: from $1-3 \mathrm{~h}$ to less than 1h). A smaller decrease in activity $(\mathrm{W}(621)=5.5+\mathrm{e} 5, \mathrm{p}<0.001$; not affecting the median) was present for doing physical activities. On the other hand, participants reported highest increase in time spent participating in online meetings $(\mathrm{W}(621)=2534, \mathrm{p}<0.001$; median +2 categories: from $1-3 \mathrm{~h}$ to 5 $10 \mathrm{~h} /$ week) and watching non-interactive audiovisual materials $(\mathrm{W}(620)=4097, \mathrm{p}<0.001$; median +1 category: from 5-10h to 10-20h/week). A smaller increase (not affecting the median) was also observed for playing computer games $(\mathrm{W}(621)=8498, \mathrm{p}<0.001)$ and doing manual activities $(\mathrm{W}(620)=9857, \mathrm{p}<0.001)$.

To further examine the pattern of life habits during COVID-19 lockdown we conducted two principal components analyses (PCA) (see Table 2). (1) The first PCA encompassed responses 
regarding frequencies of performing specific activities during the lockdown. Our analysis (model's $\mathrm{Chi}^{2}(13)=304.3, \mathrm{p}<0.001$, Oblimin rotation, minimal correlation for factor loading $\mathrm{r}=0.4$ ) revealed that life habits investigated in our study composed two independent factors (correlation between factors $r=0.08$ ). (A) The first factor consistent of items (all of them were positive factor loadings): (i) spending time outside home, (ii) meeting people outside home, (iii) physical activity, and (iv) manual work. (B) The second factor consisted of items: (i) playing computer games, (ii) watching TV and audiovisual materials, and (iii) participating in online meetings (also all responses were positive factor loadings). The results of the analysis revealed that interacting with people at one's home did not contribute to any of these factors.

(2) The second PCA was conducted on differences between life habits before and during the pandemic. The second PCA (model's Chi-squared(13) $=327.1, \mathrm{p}<0.001$, Oblimin rotation, minimal correlation for factor loading $\mathrm{r}=0.4$ ) revealed a different factorial structure than the first one. (A) The first extracted factor shows that people who were spending less time outside flat than before the pandemic were also (i) meeting relatively less people outside one's flat (than before the pandemic) and were (ii) more likely to report playing more computer games, (iii) watching more audiovisual materials and (iv) participating more in online meetings. This factor indicates that the more people were restricting their activity outside their home, the more they engaged in media consumption and digital social interactions. (B) The second factor consisted of two items which both positively loaded the factor: (i) physical activity and (ii) manual work, indicating that people who started performing more physical activity during the lockdown were also more likely to start performing more manual work, as well as the opposite: people who were doing less physical activity during the lockdown were also less likely to do manual work. The two extracted factors did not correlate with each other $(\mathrm{r}=0.003)$. Once again, social interactions in person at one's home did not load any of the extracted factors.

Table 2. Results of two principal components analyses performed on the results of the life habits survey (A) PCA of time spent on activities during the lockdown

\section{Activity}

Spending time outside one's flat/house

Playing computer games

Watching movies, TV, series etc.

Meeting people online

Meeting people in person outside

Meeting people in person at home

Doing physical activity

Doing manual work

\section{Factor 1 Factor 2 Uniqueness}

0.73 . 0.468

$0.727 \quad 0.467$

$0.447 \quad 0.782$

$0.704 \quad 0.476$

0.622 . 0.538

0.849

0.739 . 0.456

0.512 . 0.726

(B) PCA of change in doing activities before/during lockdown

\section{Activity}

Spending time outside one's flat/house

Playing computer games

Watching movies, TV, series etc.

Meeting people online

Meeting people in person outside

Meeting people in person at home

Doing physical activity

Doing manual work

\begin{tabular}{|c|c|c|}
\hline Factor 1 & Factor 2 & Uniqueness \\
\hline 0.686 & . & 0.52 \\
\hline-0.427 & . & 0.818 \\
\hline-0.566 & . & 0.654 \\
\hline-0.541 & . & 0.635 \\
\hline \multirow[t]{4}{*}{0.758} & & 0.42 \\
\hline & & 0.858 \\
\hline & 0.694 & 0.469 \\
\hline & 0.779 & 0.376 \\
\hline
\end{tabular}


Finally, we investigated how strongly each of the activities measured in our survey was related to the overall perception that lockdown influenced one's life. We have thus conducted a nonparametric correlation analysis between the estimated influence of lockdown on one's life and time spent weekly on our measured behaviours. The results revealed (Table 3) that the perceived influence of lockdown was significantly related to the change in performed activities before and during the lockdown for all activities included in our survey, except for manual work. The more people felt the influence of lockdown on their lives, (i) the less time they were spending being outside their flat/home, meeting people outside their flat/home, meeting people in their flat/home, and doing physical activities; and (ii) the more time they spent watching audiovisual materials, participating in online meetings, and playing computer games.

Table 3. Correlations between life habits and general perception that lockdown influenced one's life. Correlation with the overall perception that lockdown affected one's life

\begin{tabular}{lrrrr} 
Activity & Tau B & \multicolumn{1}{c}{ p } & \multicolumn{1}{c}{ BF10 } \\
\hline Spending time outside one's flat/house & -0.234 & $* * *$ & $<.001$ & $2.4 \mathrm{e}+15$ \\
Playing computer games & 0.127 & $* * *$ & $<.001$ & 5776 \\
Watching movies, TV, series etc. & 0.218 & $* * *$ & $<.001$ & $1.4 \mathrm{e}+13$ \\
Meeting people online & 0.188 & $* * *$ & $<.001$ & $2.540 \mathrm{e}+9$ \\
Meeting people in person outside & -0.203 & $* * *$ & $<.001$ & $1.696 \mathrm{e}+11$ \\
Meeting people in person at home & -0.202 & $* * *$ & $<.001$ & $1.241 \mathrm{e}+11$ \\
Doing physical activity & -0.097 & $* *$ & 0.003 & 37.368 \\
Doing manual work & 0.04 & & 0.249 & 0.159
\end{tabular}

The average total score in CDS-29 in our sample was $49.3(S D=35.9)$, with median at 41 points, mode at 32 points, and range between 0 and 244 points (with theoretical maximum being 290 points). The distribution of scores was strongly right-side skewed (Skewness $=1.29)$ and slightly leptokurtic (Kurtosis $=2.85)$ reflecting the fact that the majority of participants reported relatively low scores (the middle $50 \%$ of participants had scores between 23 and 68) (see Figure 2).

Figure 2. Distribution of total scores in CDS-29 in our sample.

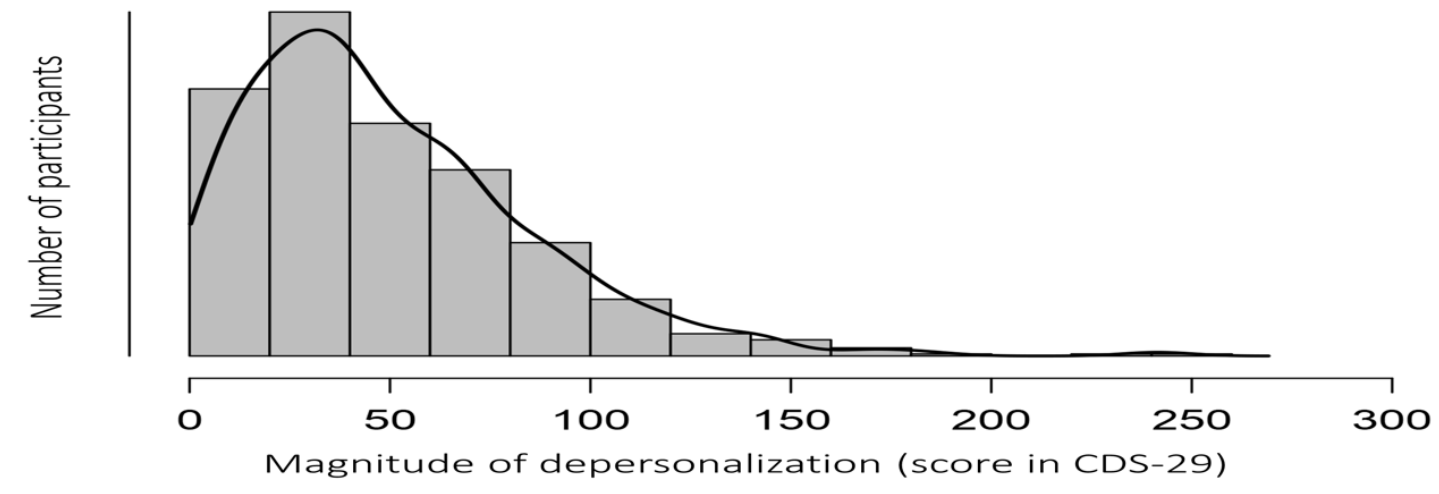

Investigating psychometric properties of CDS-29 revealed that internal reliability was similarly high to previous studies with Cronbach alpha $=0.93$. However, principal components analysis revealed a different factorial structure than previous analyses. It was also reflected by relatively high correlations between subscales as determined by (Sierra et al., 2005), which varied between Pearson's $r=0.62$ and 0.66 . Due to this, all of our reported analyses were conducted on the total score rather than the subscales. 
In order to estimate the relationship between depersonalization and life activities we conducted a correlational analysis between the score of CDS-29 and responses to questions from our survey. Table 4 presents the results of this analysis.

Table 4. Correlations between depersonalization and life habits. The table report Kendall's tau B correlations between participants' full scores in CDS-29 (measuring the extent of depersonalization experiences) and life habits during the Covid-lockdown. Items starting with "Currently:" reflect how much time participants spent doing the following activities during the lockdown. Items starting with "Change:" reflect how much more or how much less time participants spent doing the following activities during the lockdown than before (with positive values reflecting spending more time during the lockdown than before). The displayed results are uncorrected for multiple comparisons.

\section{Correlation with depersonalization (total score in CDS-29)}

\begin{tabular}{l|rlrrr} 
Item & \multicolumn{1}{c}{ Tau B } & $\mathrm{p}$ & $\mathrm{BF} 10$ & $\mathrm{BF} 01$ \\
\hline Overall influence of lockdown on life & 0.151 & $* * *$ & $<.001$ & $4.20 \mathrm{E}+05$ & $2.3 \mathrm{e}-6$
\end{tabular}

\section{Activities during lockdown}

Spending time outside one's flat/house

\begin{tabular}{|c|c|c|c|c|}
\hline-0.03 & & 0.3 & 0.1 & 9.9 \\
\hline 0.1 & $* * *$ & $<.001$ & 55.8 & 0.018 \\
\hline 0.026 & & 0.383 & 0.08 & 12.1 \\
\hline 0.077 & $* *$ & 0.008 & 3.2 & 0.32 \\
\hline-0.009 & & 0.771 & 0.056 & 17.9 \\
\hline-0.002 & & 0.947 & 0.053 & 18.9 \\
\hline-0.066 & $*$ & 0.027 & 1.073 & 0.93 \\
\hline 0.043 & & 0.15 & 0.195 & 5.1 \\
\hline
\end{tabular}

Playing computer games

Watching movies, TV, series etc.

Meeting people online

Meeting people in person outside

Meeting people in person at home

Doing physical activity

Doing manual work

$$
0.043
$$

\section{Change in doing activities in relation to before the lockdown}

\begin{tabular}{|c|c|c|c|c|c|}
\hline Spending time outside one's flat/house & -0.019 & & 0.51 & 0.068 & 14.7 \\
\hline Playing computer games & 0.138 & $* * *$ & $<.001$ & 27880 & $3.6 \mathrm{e}-5$ \\
\hline Watching movies, TV, series etc. & 0.109 & $* * *$ & $<.001$ & 194 & 0.005 \\
\hline Meeting people online & 0.054 & & 0.063 & 0.41 & 2.4 \\
\hline Meeting people in person outside & -0.015 & & 0.606 & 0.062 & 16.2 \\
\hline Meeting people in person at home & 0.023 & & 0.429 & 0.077 & 13 \\
\hline Doing physical activity & -0.027 & & 0.354 & 0.089 & 11.3 \\
\hline Doing manual work & 0.022 & & 0.476 & 0.074 & 13.6 \\
\hline
\end{tabular}

First, we found that the subjective estimation of how strongly lockdown is felt to have influenced one's life was correlated with the occurrence of depersonalization experiences. Specifically, participants that reported that lockdown had influenced their life to a greater extent also had higher scores on the CDS-29.

In regard to the specific life habits of this group, we found that higher depersonalization was positively related to social and virtual media consumption. First, participants who were spending more time during lockdown playing computer games, and who reported that they increased the time that they spent playing computer games during the lockdown (as compared to the pre-lockdown period) reported significantly stronger depersonalization symptoms. Second, consumption of passive media such as watching movies, YouTube videos and television did not positively correlate with depersonalization by itself, but people who reported that they were spending more time doing this during lockdown than before showed increased depersonalization. Finally, frequent participation in online video meetings via platforms such as Zoom, Skype, Teams, etc., positively 
correlated with depersonalization. Moreover, we found a weak significant negative correlation between the frequency of physical exercises during lockdown and the magnitude of depersonalization showing that physical exercise during lockdown was weakly correlated to lower level of depersonalization.

In contrast to social and virtual media consumption, the amount of social contact outside of the home did not influence depersonalization. Neither the absolute time spent meeting with other people in one's flat/home or outside one's flat/home, nor the difference in these activities before and after the lockdown, correlated with depersonalization, with Bayesian analyses showing strong support for null hypothesis.

Additionally, we found that change in vividness of experienced emotions was significantly related to the occurrence of depersonalization experiences. People with higher depersonalization traits experienced positive emotions less vividly (Tau $\mathrm{B}=-0.21, \mathrm{p}<0.001, \mathrm{BF} 10=2.2 \mathrm{e}+11$ ) and negative emotions more vividly (Tau $\mathrm{B}=0.19, \mathrm{p}<0.001, \mathrm{BF} 10=4.1 \mathrm{e}+9$ ) than people with lower occurrences of depersonalization experiences.

\section{Discussion}

This study examined the relationship between life habits changes before and during COVID-19 pandemic lockdown and depersonalisation experiences. Depersonalisation is a common dissociative phenomenon that makes people feel 'estranged' and detached from themselves and from their bodies (Sierra \& Berrios 1997), which in turn may lead to estrangement from others and consequent social isolation (Simeon and Abugel 2006; Sierra 2009; Perkins 2021). The COVID-19 pandemic lockdown presents an exceptional situation whereby people are strongly encouraged to keep a safe distance from others, that is, to 'detach' or physically isolate from other people and to interact less with their surroundings (e.g. fear of contamination by touching objects, of breathing infected air, etc.). Previous research has shown the critical importance of dynamic, embodied and multisensory interactions with the social and physical environment for one's sense of self and mental health (Ciaunica 2017; Fotopoulou \& Tsakiris 2017; Ciaunica et al. 2018, 2021a). Here we aimed at exploring the relationship between lockdown-related restrictions and experiences of depersonalisation.

Our study revealed several key findings. First, we found that increased use of digital media-based activities (especially playing computer games) correlated with higher feelings of depersonalisation. Strikingly, increased participation in online social e-meetings via technology-based platforms such as Zoom, Teams, Skype, etc., (as opposed to pre-lockdown period), also positively correlated with depersonalisation experiences. We also found that people who reported that they were spending more time during the lockdown engaged in sedentary digital media-consumption such as watching films, TV, YouTube videos (as opposed to pre-lockdown period), also showed depersonalisation traits. Moreover, people reporting higher experiences of DP in our survey also reported enhanced vividness of negative emotions (as opposed to positive emotions). Our study also reveals a weak significant negative correlation between the frequency of physical exercise during the lockdown and the occurrence of depersonalisation experiences. Intriguingly, the amount of social interactions, both in person at home and outdoors, did not influence depersonalization, with Bayesian analyses showing strong support for a null hypothesis. Finally, our results suggest that the subjective estimation of how strongly lockdown restrictions influenced one's life was related to the occurrence of depersonalization experiences. Specifically, participants that reported that lockdown influenced their life to greater extent, had higher scores in CDS-29. Below we discuss these findings in detail. 
One main finding is that increased use of digital media-based activities correlated with higher occurrences of depersonalisation experiences. Specifically, participants who reported (a) spending more time during lockdown playing computer games, and (b) increasing the time that they spent playing computer games during the lockdown (as compared to the pre-lockdown period), showed significantly higher depersonalisation traits. While the direction of causation between these two phenomena is currently an open question, one may speculate around potential explanatory factors. For example, one may argue that computer-based gaming involves restricted and repetitive proprioceptive and proximal tactile stimulation (e.g. fingers on the keyboard, the mouse, or the telecommand, feet on the floor, sedentary posture, etc.). Indeed, videogaming, as the label suggests, rests heavily on enhanced visual and auditory sensory stimulation, to the detriment of proprioceptive, interoceptive, olfactory and tactile stimulation. This imbalance towards exteroceptive stimuli (being overstimulated by the outside or the 'virtual' world 'out there' may explain why people who spend more time videogaming also report higher feelings of selfdetachment and disembodiment (lack of presence in the real world).

Another potential interpretation is that by disengaging from bodily signals, people may become more tempted to get more attentionally and emotionally involved in virtual realities than the real one. For example, playing computer games involves attentional detachment from both physical reality in favour of immersion in a virtual one, as well as detachment from one's body in favour of embodiment of one's digital body - an avatar (Bailenson, 2018; Yee \& Bailenson, 2007). Previous work outlined that the sense of self is critically dependent on bodily (i.e. interoceptive and proprioceptive) sensory processing (Gallagher 2000; Damasio 2000; Ciaunica \& Fotopoulou 2017; Seth \& Tsakiris 2018; Woźniak, 2019). If this is so, then (1) distracting oneself from one's somatic feelings via digital audiovisual materials that puts the body in a more passive setting, should lead to increased depersonalization. (2 By contrast, higher dynamical and embodied engagements with the surroundings should lead to lower depersonalization. Our findings seem to provide a significant support for (1) and a weak significant support for (2). Indeed, we found a weak significant negative correlation between the frequency of physical exercise during the lockdown and the occurrence of depersonalisation experiences. This suggests that physical exercise (i.e. dynamic activity engaging the entire moving body) may be related to lower depersonalisation. This idea is in line with previous work outlining that depersonalization is underpinned by disrupted bodily sensory processing as demonstrated by several studies (Sierra et al., 2002; Lemche, Brammer, et al., 2013; Medford et al., 2016; Dewe et al., 2018; Farmer et al. 2020; Woźniak, McEllin, Hohwy, Ciaunica, preprint). One may also speculate that people that typically spend a considerable amount of time videogaming (regardless of the pandemic status) are more introverted by trait (hence prone to DP), avoiding in-person social interactions in real life, which may be experienced as potential stressors.

Another important finding is that increased participation in online social e-meetings via technologybased platforms such as Zoom, Teams, Skype, etc., (as opposed to pre-lockdown period), positively correlated with depersonalisation experiences. The absolute time spent on e-meetings during the lockdown was positively related to increased depersonalization, while the difference between lockdown and pre-lockdown did not reveal any effect. Again, while the direction of the causation between these phenomena remains to be further investigated, here we can speculate in favour of the impact of diminished dynamic and multisensory, proximal interactions with the physical and social environment on one's sense of self. Indeed, during technology-mediated social interactions via platforms such as Zoom, Skype, Teams, etc, the body posture is primarily sedentary. Moreover, the communication is primarily audiovisual in a flat two-dimensional space, lacking the richness of the multisensory cues and affective reward that people typically gain from face-to-face in person interactions. Enhanced use of audiovisual signals situated 'out there' may prompt people to disengage, detach and pay less attention to bodily signals from 'here', that is inside and closer to the physical body (Ciaunica \& Fotopoulou 2017; Ciaunica et al. 2021a). This hypothesis seems to receive further support from a recent study exploring the relationship between social touch 
deprivation and psychological wellbeing during COVID-19. Von Mohr and colleagues (2021) found that the more intimate touch experienced during the COVID-19 pandemic, the better the targeted psychological outcomes, namely self-reported anxiety, feelings of loneliness, general mental health and perceived tolerance for isolation.

In addition, we found that people reporting higher experiences of DP in our survey also reported enhanced vividness of negative emotions (as opposed to positive emotions), which can be linked to higher anxiety and stress due to the uncertainty and threat posed by the COVID-19 pandemic. This is in line with previous work suggesting that a core feature of DP is atypical emotional processing: "I don't have any emotions- it makes me so unhappy" (Medford 2012, see also Sierra et al.,2002). As Medford notes, this may seem self-contradictory, but on further questioning, the patient explained that he experienced considerable inner turmoil, but felt reduced emotional response to external events or other people. Again, this is in line with the idea that DP involves feelings of being simultaneously 'trapped' in one's mind, and outside one's body, with enhanced focus on inner workings to the detriment of active and affective responsiveness to the external environment (Gerrans 2018; Ciaunica et al. 2020; 2021a).

Intriguingly, the number of social interactions, both in person at home and outdoors, did not influence depersonalization, with Bayesian analyses showing strong support for a null hypothesis. This may be due however to a potential flooring/ceiling effect, as people were explicitly instructed to avoid in-person social interactions as much as possible. Indeed, given that (a) the largest decrease of self-reported activity during the lockdown (as opposed to pre-pandemic) was the time spent meeting people in person outside or inside one's home, and (b) we don't know to what extent these indoors and outdoors meetings involved close, touch-based social interactions (e.g. hugging vs saying 'hello' from safe distance), the relationship between social contact and depersonalisation remains inconclusive at this stage. Further work needs to disentangle different aspects of social experiences (distal vs proximal) and depersonalisation.

Finally, our results suggest that the subjective estimation of how strongly lockdown restrictions influenced one's life was related to the occurrence of depersonalization experiences. Specifically, participants that reported that lockdown influenced their life to greater extent, had higher scores in CDS-29. Although our study did not involve a systematic comparison of the same individuals before the pandemic and during its course (see Limitations section below), our findings strongly suggest that the experience of lockdown also led to increase in depersonalization experiences. Indeed, lockdown-related restrictions led to a wide-spread increase in anxiety and stress (see Froese et al. 2021), which, combined with lack of proximal social interactions and increased digital-media consumption, may lead to depersonalization experiences. On the other hand, since this study does not determine the direction of causation, it is also possible that people with higher depersonalization traits might be simply more likely to be sensitive to lockdown-related changes and hence report them as more strongly affecting this life. If the second hypothesis is correct, then on average participants tested during the lockdown should not differ in the occurrence of depersonalization from people tested before the COVID-19 pandemic. Although our study did not directly investigate this issue, comparison of our results with the results of previous studies suggests that people were on average reporting much stronger depersonalization experiences than before.

For example, (Aponte-Soto et al., 2014) published a study with 300 Italian participants where they reported mean general score in CDS-29 (?) at the level of $M=16.3(S D=18.3$, range $=0-132)$. They also reported that only $2 \%$ ( 6 participants) obtained a score of $\geq 70$ indicating, according to them, clinically significant depersonalization symptoms. In contrast, in our study the average score was much higher and reached $M=49.3(S D=35.9$, range $=0-244)$, and almost a quarter of participants $(24 \%)$ obtained clinically significant scores $\geq 70$. Other, smaller studies reported similar values to Aponte-Soto et al's: (Sugiura et al., 2009) in a Japanese version of CDS-29 tested on a Japanese 
population found that the average score in a control group that was not diagnosed with depersonalization was $M=15.1(S D=16.5)$. (Zingrone, Alvarado, \& Agee, 2009) conducted another two large questionnaire studies with CDS-29 and found a relatively large average score on CDS-29 in their samples: Study 4: $\mathrm{n}=256, M=20.1, S D=19.4$, range=0-93; Study 5: $\mathrm{n}=591, M=37.2$, $S D=14.2$, range $=0-279$. However, while Study 4 was conducted on a random sample of a small city in central Virginia, USA, study 5 was conducted on subscribers of a para-psychology email newsletter. However, people interested in parapsychology might have the tendency to report more uncommon experiences than the rest of the population. Thus, the results of Zingrone and colleagues' study 5 might reflect elevated average depersonalization experiences compared with the rest of population.

More indirect evidence in support of the idea that lockdown-related experiences may lead to depersonalisation comes from the finding that in our sample the correlation between the CDS-29 subscales was higher than in previous studies. This suggests a more homogenous and global phenomenon, consistent with the fact that a significant amount of people worldwide experienced similar restrictions and ensuing negative states due to the pandemic. Overall, while our study does not provide direct ultimate evidence that COVID-19 lockdown was causally responsible for an increase in the occurrences of experiences of depersonalization, it suggests that this is the case when our results are compared with the results of previous studies that used CDS-29.

There are several limitations of our study. Ideally, the same participants who took part in our online study should have been assessed for their depersonalisation traits before the pandemic. However, the occurrence of the COVID-19 pandemic was unforeseeable, hence our study was tailored 'on the fly' to assess lockdown-related experiences pre- vs during the pandemic as self-reported during the pandemic. Further work needs to contrast depersonalisation experiences pre-pandemic versus during the pandemic in the same large sample of participants. Second, our study was conducted between April and May 2021, and both the CDS-29 and our tailored lockdown survey were asking participants about their experiences in the previous 6 months. It means that participants were describing their lives during late autumn, winter, and early spring, as most of our participants were European-based. It is possible that life activities reported by participants were strongly influenced by the fact that participants were asked about the cold period of the year. However, this should not affect correlations with CDS-29. Finally, as we mentioned earlier, our study did not collect specific data about the type of in person interactions (distal versus proximal / romantic versus friends) that people had both indoors and outdoors during the pandemic.

\section{Conclusion}

This study looked at a potential relationship between lockdown-related experiences and depersonalisation, a condition that makes people feel detached from their self, body and the world. The underlying assumption was that being detached or estranged from others may lead to feeling detached and estranged from oneself. The exceptional pandemic context created the condition in which one can observe simultaneously (1) a sharp decrease in dynamical and proximal interactions with the environment (people move less, interact less and touch less the surroundings and others); (2) and a sharp increase in digital and distal media interactions (where the audio-visual modalities are predominant, and the bodily movements and activities are more limited).

Our results revealed that increased use of (1) sedentary digital media-consumption (watching films, TV, YouTube videos, etc.) and (2) digital media-based activities - especially playing computer games and participation in online social e-meetings via platforms such as Zoom, Teams, Skype, etc., - correlated with higher feelings of depersonalisation. We also found that people reporting 
higher experiences of depersonalisation also reported enhanced vividness of negative emotions (as opposed to positive emotions). In addition, a weak significant negative correlation has been highlighted between the frequency of physical exercise during the lockdown and the occurrence of depersonalisation experiences. Importantly, participants that reported that lockdown influenced their life to greater extent, had also higher occurrences of DP experiences.

Our findings may help tackle key questions related to the human mental well-being during a lockdown, in the general population. This study suggests that paradoxically, increasing virtual (i.e. distal, sedentary and screen-based) social interactions and digital activities may have negative effects in some people, by making them feel less 'real' and more detached from one's self, body and others. These results point to potential risks related to an overly sedentary and hyper-digitalized life habits that may induce feelings of living in one's head, disconnected from one's body, self and the world. 


\section{References}

1. Alzueta, E., Perrin, P., Baker, F. C., Caffarra, S., Ramos-Usuga, D., Yuksel, D., \& Arango-Lasprilla, J. C. (2021). How the COVID-19 pandemic has changed our lives: A study of psychological correlates across 59 countries. Journal of clinical psychology, 77(3), 556-570.

2. Aponte-Soto, M. R., Vélez-Pastrana, M., Martínez-Taboas, A., \& González, R. A. (2014). Psychometric properties of the Cambridge depersonalization scale in Puerto Rico. Journal of Trauma \& Dissociation, 15(3), 348-363.

3. Bailenson, J. (2018). Experience on demand: What virtual reality is, how it works, and what it can do: WW Norton \& Company.

4. Blanke, O., \& Metzinger, T. K. (2009). Full-body illusions and minimal phenomenal selfhood. Trends in Cognitive Sciences, 13(1), 7-13. https://doi.org/10.1016/j.tics.2008.10.003

5. Brooks, S. K., Webster, R. K., Smith, L. E., Woodland, L., Wessely, S., Greenberg, N., \& Rubin, G. J. (2020). The psychological impact of quarantine and how to reduce it: rapid review of the evidence. The Lancet, 395(10227), 912-920.

6. Carel H, Ratcliffe M, Froese T. Reflecting on experiences of social distancing. Lancet. (2020) 396:87-8. doi: 10.1016/S0140-6736(20)31485-9

7. Ciaunica, A. (2017). 'The Meeting of Bodies: Basic Forms of Shared Experiences, Topoi, an International Journal of Philosophy. https://doi.org/10.1007/s11245-017-9500-x

8. Ciaunica, A. \& Fotopoulou, A., 2017. 'The Touched Self: Psychological and Philosophical Perspectives on Proximal Intersubjectivity and the Self'. In Durt C., Fuchs T., and Tewes C. (eds). Embodiment, Enaction, and Culture-Investigating the Constitution of the Shared World. Cambridge MA: MIT Press.

9. Ciaunica, A., Charlton, J., 2018. When the self slips: what depersonalization can say about the self https://aeon.co/essays/what-can-depersonalisation-disorder-say-about-the-self

10. Ciaunica, A., Schilbach, L., \& Deroy, O. (2018) The multisensory base of bodily coupling in faceto-face social interactions: Contrasting the case of autism with the Möbius syndrome, Philosophical Psychology, 31:8,1162-1187

11. Ciaunica, A., Charlton, J. \& Farmer, H. (2020) - When the Window Cracks: Transparency and the Fractured Self in Depersonalisation. Phenomenology and Cognitive Science https://doi.org/10.1007/s11097-020-09677-z

12. Ciaunica, A., Hesp, C., Seth, A., Limanowski, J., \& Friston, K. (2021a, February 23). I overthinktherefore I am not: Altered Sense of Self and Agency in Depersonalisation Disorder. https://doi.org/10.31234/osf.io/k9d2n

13. Ciaunica A, Roepstorff A, Fotopoulou AK and Petreca B (2021b) Whatever Next and Close to My Self-The Transparent Senses and the "Second Skin": Implications for the Case of Depersonalization. Front. Psychol. 12:613587. doi: 10.3389/fpsyg.2021.613587

14. Damasio, A., (2000): The Feeling of What Happens. Body, Emotion and the Making of Consciousness, London: Vintage.

15. Deroy, O., Chen, Y. C., \& Spence, C. (2014). Multisensory constraints on awareness. Philosophical Transactions of the Royal Society B: Biological Sciences, 369(1641), 20130207.

16. Dimmock J, Krause AE, Rebar A, Jackson B. Relationships between social interactions, basic psychological needs, and wellbeing during the COVID- 19 pandemic. Psychol Health. (2021). doi: 10.1080/08870446.2021.1921178. [Epub ahead of print].

17. Dixon, J., 1963. Depersonalization phenomena in a sample population of college students. The British journal of psychiatry 109, 371-375.

18. de Jaegher, H. \& E. Di Paolo. (2007). 'Participatory sense-making: An enactive approach to social cognition'. Phenomenology and the Cognitive Sciences 6: 485-507.

19. Dewe, H., Watson, D.G., Kessler, K., Braithwaite, J.J., 2018. The depersonalized brain: New evidence supporting a distinction between depersonalization and derealization from discrete patterns of autonomic suppression observed in a non-clinical sample. Conscious. Cogn. 63, 29-46.

20. Fagioli, F., Telesforo, L., Dell'Erba, A., Consolazione, M., Migliorini, V., Patane, M., . . . FioriNastro, P. (2015). Depersonalization: An exploratory factor analysis of the Italian version of the Cambridge Depersonalization Scale. Comprehensive psychiatry, 60, 161-167. 
21. Farmer, H., Cataldo, A., Adel, N., Wignall, E., Gallese, V., Deroy, O., Hamilton, A., \& Ciaunica, A. (2020). The Detached Self: Investigating the Effect of Depersonalisation on Self-Bias in the Visual Remapping of Touch, Multisensory Research, , 1-22. doi: https://doi.org/10.1163/22134808bja10038

22. Froese T, Broome M, Carel H, Humpston C, Malpass A, Mori T, Ratcliffe M, Rodrigues J and Sangati F (2021) The Pandemic Experience: A Corpus of Subjective Reports on Life During the First Wave of COVID-19 in the UK, Japan, and Mexico. Front. Public Health 9:725506. doi: 10.3389/fpubh.2021.725506

23. Gallagher, S. (2000). Philosophical conceptions of the self: Implications for cognitive science. Trends in Cognitive Sciences, 4(1), 14-21.

24. Gallese V. (2014) Bodily selves in relation: embodied simulation as second-person perspective on intersubjectivity. Philos Trans R Soc Lond B Biol Sci. 2014 Apr 28;369(1644):20130177. doi: 10.1098/rstb.2013.0177.

25. Gerrans, P. (2018). Depersonalisation Disorder Affective Processing and Predictive Coding. Review of Psychology and Philosophy. doi.org/10.1007/s13164-018-0415-2 25

26. Ionta S, Gassert R, Blanke O. Multi-sensory and sensorimotor foundation of bodily selfconsciousness - an interdisciplinary approach. Front Psychol. 2011 Dec 23;2:383. doi: 10.3389/fpsyg.2011.00383.

27. Hunter EC., Sierra M, David AS (2004) The epidemiology of depersonalization and derealisation. A systematic review. Society of Psychiatry Psychiatric Epidemiology39: 9- 18.

28. Hunter, E.C., Charlton, J., David, A.S., 2017. Depersonalisation and derealisation: assessment and management. BMJ 356, j745.

29. Hohwy, J. 2007 The Sense of Self in the Phenomenology of Agency and Perception, Psyche 13 (1), pp. 1-20.

30. Kiverstein, J. Free Energy and the Self: An Ecological-Enactive Interpretation. Topoi 39, 559-574 (2020). https://doi.org/10.1007/s11245-018-9561-5

31. Legrand, D. (2006).The bodily self: the sensorimotor roots of pre-reflective self-consciousness. Phenomenology and Cognitive Sciences 5, 89-118.

32. Lee WE, Kwok CH, Hunter EC, Richards M, David AS (2012) Prevalence and childhood antecedents of depersonalization syndrome in a UK birth cohort. Soc Psychiatry Psychiatr Epidemiol 47: 253-261.

33. Lemche, E., Brammer, M.J., David, A.S., Surguladze, S.A., Phillips, M.L., Sierra, M., Williams, S.C., Giampietro,V.P., 2013. Interoceptive-reflective regions differentiate alexithymia traits in depersonalization disorder. Psychiatry Research: Neuroimaging 214, 66-72.

34. Medford, N., 2012. Emotion and the unreal self: depersonalization disorder and de-affectualization. Emot. Rev. 4, 139-144

35. Medford, N., Sierra, M., Stringaris, A., Giampietro, V., Brammer, M.J., David, A.S., 2016. Emotional experience and awareness of self: functional MRI studies of depersonalization disorder. Front. Psychol. 7, 432.

36. Michal, M., Reuchlein, B., Adler, J., Reiner, I., Beutel, M.E., Vögele, C., Schächinger, H., Schulz, A., 2014. Striking discrepancy of anomalous body experiences with normal interoceptive accuracy in depersonalization- derealization disorder. PLoS One 9, e89823.

37. Migliorini, V., Dell'Erba, A., Fagioli, F., Sierra, M., Mosticoni, S., Telesforo, L., . . Fiori-Nastro, P. (2012). Italian (cross cultural) adaptation and validation of the Cambridge Depersonalization Scale (CDS). Epidemiology and psychiatric sciences, 21(2), 221-226.

38. Perkins, J. (2021). Life on Autopilot - A Guide to Living with Depersonalisation Disorder. Jessica Kingsley Publishers

39. Qin P, Wang M, Northoff G. Linking bodily, environmental and mental states in the self-A threelevel model based on a meta-analysis. Neurosci Biobehav Rev. 2020 Aug;115:77-95. doi: 10.1016/j.neubiorev.2020.05.004.

40. Richardson, M. J., Marsh, K. L., Isenhower, R. W., Goodman, J. R., and Schmidt, R. C. (2007). Rocking together: dynamics of intentional and unintentional interpersonal coordination. Human Movement. Science 26, 867-891.

41. Rubin GJ, Wessely S. The psychological effects of quarantining a city. BMJ. (2020) 368:m313. doi: 10.1136/bmj.m313 
42. Salami A, Andreu-Perez J, Gillmeister H. Symptoms of depersonalisation/derealisation disorder as measured by brain electrical activity: A systematic review. Neurosci Biobehav Rev. 2020 Nov;118:524-537. doi: 10.1016/j.neubiorev.2020.08.011.

43. Salari N, Hosseinian-Far A, Jalali R, Vaisi-Raygani A, Rasoulpoor S, Mohammadi M, et al. Prevalence of stress, anxiety, depression among the general population during the COVID-19 pandemic: a systematic review and meta-analysis. Global Health. (2020) 16:57. doi: 10.1186/s12992-020-00589-w

44. Sebanz, N., Bekkering, H. \& Knoblich, G. (2006) Joint action: Bodies and minds moving together. Trends in Cognitive Sciences 10(2):70-76.

45. Seth, A. K., Suzuki, K., and Critchley, H. D. (2012). An interoceptive predictive coding model of conscious presence. Front. Psychol. 2:395. doi: 10.3389/fpsyg. 2011.00395

46. Seth, A., \& Tsakiris, M. (2018). Being a beast machine: The somatic basis of selfhood. Trends in Cognitive Sciences 22 (11):969-981.

47. Schilbach, L., Timmermans, B., Reddy, V., Costall, A., Bente, G., Schlicht, T. 2013. Toward a second-person neuroscience. Behavioral and Brain Sciences 36, 393-414.

48. Sierra M., Berrios GE. (1998) Depersonalization: neurobiological perspectives. Biological Psychiatry 44:898-908

49. Sierra, M., Baker, D., Medford, N., \& David, A. S. (2005). Unpacking the depersonalization syndrome: an exploratory factor analysis on the Cambridge Depersonalization Scale. Psychological Medicine, 35(10), 1523-1532.

50. Sierra, M., \& Berrios, G. E. (2000). The Cambridge Depersonalisation Scale: A new instrument for the measurement of depersonalisation. Psychiatry research, 93(2), 153-164.

51. Sierra, M., \& David, A. S., 2011. Depersonalization: a selective impairment of self-awareness. Consciousness and cognition, 20(1), 99-108.

52. Simeon, D., Abugel J. (2006). Feeling Unreal: Depersonalization Disorder and the Loss of the Self. Oxford University Press.

53. Sugiura, M., Hirosawa, M., Tanaka, S., Nishi, Y., Yamada, Y., \& Mizuno, M. (2009). Reliability and validity of a Japanese version of the Cambridge depersonalization scale as a screening instrument for depersonalization disorder. Psychiatry and clinical neurosciences, 63(3), 314-321.

54. Tsakiris M. (2017) The multisensory basis of the self: From body to identity to others. Quarterly Journal of Experimental Psychology. 2017;70(4):597-609.

55. Von Mohr, M., Kirsch, L. P., \& Fotopoulou, A. (2021, February 18). Social touch deprivation during COVID-19: effects on psychological wellbeing, tolerating isolation and craving interpersonal touch. https://doi.org/10.31234/osf.io/vkzft

56. Woźniak, M. (2019). How to grow a self: development of the self in a Bayesian brain. doi:https://doi.org/10.31234/osf.io/6e3ad

57. Woźniak, M., McEllin, L., Hohwy, J., \& Ciaunica, A. (in prep.). Depersonalization influences selfprioritization of bodily, but not abstract stimuli.

58. Xiong J, Lipsitz O, Nasri F, Lui LM, Gill H, Phan L, et al. Impact of COVID-19 pandemic on mental health in the general population: a systematic review. J Affect Disord. (2020) 277:55-64. doi: 10.1016/j.jad.2020.08.001

59. Yee, N., \& Bailenson, J. (2007). The Proteus effect: The effect of transformed self-representation on behavior. Human communication research, 33(3), 271-290.

60. Zingrone, N. L., Alvarado, C. S., \& Agee, N. (2009). Psychological correlates of aura vision: Psychic experiences, dissociation, absorption, and synaesthesia-like experiences. Australian Journal of Clinical \& Experimental Hypnosis, 37(2).

61. Zmigrod, S., Hommel B. (2013). Feature Integration across Multimodal Perception and Action: A Review. Multisensory Research 26 (2013) 143-157. 


\section{Author contributions}

AC, MW and JK designed the study. LM and MW collected and analysed the data. AC wrote the first draft of the manuscript. MW wrote the Methods and Results sections. LM, JK, MW, VG, JH revised the final version of the manuscript.

\section{Funding}

This work was supported by was supported by (i) a FCT grant PTDC/FER-FIL/4802/2020 and Bial grant $\mathrm{n}^{\circ}$ 157/16 to AC; (ii) the European Research Council (ERC) n 679092 to LM; (iii) the European Research Council n 691790 to JK; (iv) JH is supported by the Three Springs Foundation through the Centre for Consciousness \& Contemplative Studies; (v) MW was supported by an ERC grant $n^{\circ} 609819$

\section{Competing Interests Statement}

All authors declare no competing interests. 